\title{
Guar bread: acceptability and efficacy combined. Studies on blood glucose, serum insulin and satiety in normal subjects
}

\author{
By P. R. ELLIS AND E. C. APLING \\ Department of Food Science, University of Reading, London Road, \\ Reading, Berks. RGI 5AQ \\ AND A. R. LEEDS AND N. R. BOLSTER \\ Department of Nutrition, Queen Elizabeth College, University of London, \\ Campden Hill Road, Kensington, London W8 7AH
}

(Received 5 January 1981-Accepted 30 April 1981)

\begin{abstract}
1. Bread alone and supplemented with guar gum at three levels $(50,100$ and $150 \mathrm{~g} / \mathrm{kg})$ was given to eleven non-diabetic subjects, and blood glucose and serum insulin were determined preprandialy, and at $30 \mathrm{~min}$ and $60 \mathrm{~min}$ after commencement of the meal. The satiating effect, up to $120 \mathrm{~min}$, of the guar bread and its acceptability to the same group of normal volunteers was also studied.

2. No significant differences in blood glucose were observed between control and guar breads at $30 \mathrm{~min}$ and $60 \mathrm{~min}$, apart from $100 \mathrm{~g}$ guar $/ \mathrm{kg}$ bread at $30 \mathrm{~min}(P<0.05)$. A significant difference in serum insulin was indicated between: control and $50(P<0.02)$ and $150(P<0.02)$ guar $/ \mathrm{kg}$ breads at $30 \mathrm{~min}$; control and 50 $(P<0.05), 100(P<0.001)$ and $150(P<0.05) \mathrm{guar} / \mathrm{kg}$ breads at $60 \mathrm{~min}$.

3. There were no significant differences in the satiety scores for control and guar breads. Significant increases in satiety attributed to $150 \mathrm{~g} \mathrm{guar} / \mathrm{kg}$ bread were found when compared to: $50 \mathrm{~g} \mathrm{guar} / \mathrm{kg}$ bread immediately after eating $(P<0.05), 100 \mathrm{~g}$ guar $/ \mathrm{kg}$ bread at $60 \mathrm{~min}(P<0.02)$ and 50 and $100 \mathrm{~g}$ guar $/ \mathrm{kg}$ breads at $120 \mathrm{~min}$ (both $P<0.05$ ).

4. There was a positive correlation between hedonic score and relative replacement of guar $(r 0.62, P<0.001$, $n 44)$ and from the regression line it was found that 50 and $100 \mathrm{~g}$ guar $/ \mathrm{kg}$ breads produced hedonic scores close to a neutral response of 5 , wherea: $150 \mathrm{~g}$ guar $/ \mathrm{kg}$ bread at a predictive score of 6.3 appeared to be unacceptable to our subjects.

5. Guar bread at the $100 \mathrm{~g} / \mathrm{kg}$ level $(59 \mathrm{~g}$ guar $/ \mathrm{kg}$ bread) reduced the serum insulin by $48 \%$ at $60 \mathrm{~min}$ and is found to be an acceptable food product at this level of incorporation. However, more information is required to demonstrate the possible satiating potential of guar bread.
\end{abstract}

Guar gum, a high-molecular-weight galactomannan, is produced from the seed cotyledon of the cluster bean Cyamopsis tetragonolobus (L.). This non-absorbable polysaccharide (termed dietary fibre) has been shown to be of therapeutic value in the treatment of diabetes for a period of up to 1 year (Jenkins, Wolever, Taylor, Reynolds et al. 1980). Incorporating guar gum into carbohydrate-containing meals has been shown to reduce postprandial hyperglycaemia and insuliniemia in both normal (Jenkins, Leeds et al. 1977) and diabetic subjects (Jenkins et al. 1976). Other types of dietary fibre behave in a similar fashion but guar gum seems to be the most effective (Jenkins, Wolever, Leeds et al. 1978). A significant reduction in $24 \mathrm{~h}$ urinary glucose output in diabetics following administration of $25 \mathrm{gguar} / \mathrm{d}$ in bread, soup and either fruit juice or mashed potato has been shown by the same group (Jenkins, Wolever et al. 19:7).

Guar gum forms viscous colloidal dispersions at low concentrations when hydrated in cold water, and it has been suggested that the rheological character of guar gum and other such gel-forming polysaccharides is responsible for the clinical effect (Jenkins, Wolever, Leeds $e$ t al. 1978). The mechanism appears to involve a reduction in the rate of absorption of glucose, which may be due to delayed gastric emptying (Holt et al. 1979; Leeds et al. 1979) and a reduced rate of absorption of glucose from the lumen of the small intestine (Jenkins, 1980). The change of nature of the contents of the gut caused by mixing guar gum 
with food may modify release of gastrointestinal hormones involved in modification of insulin release, gastrointestinal motility and morphology. Abnormally high levels of gastric inhibitory polypeptide and enteroglucagon, occurring after test meals in patients with the dumping syndrome, do not occur after test meals thickened with pectin (Jenkins, Bloom et al. 1980).

Apling et al. (1977) high-lighted the main problems of incorporating large amounts of guar gum into food systems which would then be acceptable for eating. Bread was suggested as being perhaps the most useful vehicle. Preliminary studies by Tredger \& Ransley (1978) have shown that it is possible to incorporate guar gum into a variety of baked products which are suitable for, and acceptable to, diabetic patients. A guar crispbread has been used successfully to treat diabetic patients (Jenkins, Wolever, Nineham et al. 1978). More recently, Hill \& Leeds (1979) investigated the problems of incorporating guar gum into many different food vehicles and suggested that guar gum was least unacceptable when given in relatively dry foods. However, the clinical efficacy of guar gum seems to be increased when the gum is carried in a more hydrated food system (Wolever et al. 1979). Nevertheless, from a palatability aspect semi-moist foods such as bread (Apling et al. 1978) may prove to be the more desirable vehicle for high levels of guar gum.

The objective of this study was to determine the amount of guar gum required to be added to a wheat-flour bread, to produce a significantly reduced hyperglycaemic and insulinaemic response in non-diabetic volunteers. A satiety study on the extent of hunger or fullness as a result of eating guar bread, and an acceptability study of our guar bread product were also carried out with the same group of subjects.

\section{EXPERIMENTAL METHODS \\ Glucose-insulin study}

Viscosity. Colloidal suspensions of guar gum are non-Newtonian in character; to be more specific, guar solutions exhibit pseudoplastic or shear-thinning behaviour, i.e. with increasing shear rates their apparent viscosity decreases (Goldstein et al. 1973).

To produce a guar gum suspension, the dry gum (Dealca RG30, refined guar gum; Hercules Ltd, 20 Red Lion Street, London WC1R 4PB) was first dispersed in methanol $(2.5 \mathrm{ml} / \mathrm{g}$ solid) to facilitate hydration and then finally made up with distilled water. Viscosity measurements were made with a Brookfield Synchro-Lectric RVT instrument (Baird \& Tatlock, Freshwater Road, Chadwell Heath, Essex) using spindle size 3 at a speed of $20 \mathrm{rev} . / \mathrm{min}$ and a Haake Rotoviscometer, Model RV3 (MSE Instruments, Manor Royal, Crawley, West Sussex).

Readings were taken $24 \mathrm{~h}$ after hydration at $25^{\circ} ; 10 \mathrm{~g}$ guar gum (dry weight)/l suspension of Dealca RG30 produced, as measured by the Brookfield, an apparent viscosity of $3.22 \mathrm{Ns} / \mathrm{m}^{2}(3225 \mathrm{cP})$; or, as measured by the Haake rotoviscometer, an apparent viscosity of $0.48 \mathrm{Ns} / \mathrm{m}^{2}(478 \mathrm{cP})$ at a shear rate of $100 / \mathrm{s}$.

Preparation and presentation of bread. Control and guar breads were prepared according to Apling et al. (1978) based on the simple lean recipe of the Chorleywood Bread Process (Chamberlain et al. 1962; Axford et al. 1963). Guar gum (Dealca RG30) was incorporated as replacement of wheat flour (Canadian Springs Coronet) at 50,100 and $150 \mathrm{~g} / \mathrm{kg}$ levels, using water absorption of guar-flour mixes of 75,96 and $120 \%$, respectively. Water absorption used for the control flour was $63 \%$ (water absorption $\%=\mathrm{g}$ water added $/ 100 \mathrm{~g}$ flour mixture).

For presentation to the subjects the control and test loaves were quartered so that each piece consisted of similar proportions of crust and crumb, containing the same amount of carbohydrate, guar gum and other constituents. This was necessary in order to overcome the problems of the moisture gradient in the bread which varies from an area of high moisture content at the centre of the loaf to the relatively drier region of the crust. 
Table 1. Control and test breads as presented to subjects in glucose-insulin study

\begin{tabular}{clccc}
\hline \hline $\begin{array}{c}\text { Meal } \\
\text { no. }\end{array}$ & Description of meal & Flour:guar & $\begin{array}{c}\text { Wt of } \\
\text { loaf }(\mathrm{g})\end{array}$ & $\begin{array}{c}\text { Starch } \\
\text { content }(\mathrm{g})\end{array}$ \\
\hline 1 & 50 g starch control & $100: 0$ & 100 & 50 \\
2 & 150 g guar $/ \mathrm{kg}$ bread & $85: 15$ & 100 & 31 \\
3 & 100 g guar $/ \mathrm{kg}$ bread & $90: 10$ & 100 & 37 \\
4 & $50 \mathrm{~g}$ guar $/ \mathrm{kg}$ bread & $95: 5$ & 100 & 44 \\
5 & Control for $150 \mathrm{~g} / \mathrm{kg}$ & $100: 0$ & 62 & 31 \\
6 & Control for $100 \mathrm{~g} / \mathrm{kg}$ & $100: 0$ & 74 & 37 \\
7 & Control for $50 \mathrm{~g} / \mathrm{kg}$ & $100: 0$ & 88 & 44 \\
8 & 50 g starch control & $100: 0$ & 100 & 50 \\
\hline
\end{tabular}

Table 2. Composition $(\mathrm{g} / \mathrm{kg})$ of control and test breads (by calculation)

\begin{tabular}{|c|c|c|c|c|c|c|c|c|c|}
\hline \multirow[b]{2}{*}{$\begin{array}{l}\text { Guar gum } \\
\text { replacement }\end{array}$} & \multirow[b]{2}{*}{ Moisture } & \multirow[b]{2}{*}{ Protein } & \multirow[b]{2}{*}{ Fat } & \multirow[b]{2}{*}{ Ash } & \multicolumn{2}{|c|}{ Total dietary fibre } & \multirow[b]{2}{*}{$\begin{array}{c}\text { Available } \\
\text { carbohydrate } \dagger\end{array}$} & \multirow[b]{2}{*}{$\begin{array}{l}\text { Guar } \\
\text { gum }\end{array}$} & \multirow{2}{*}{$\begin{array}{l}\text { Total } \\
\text { energy } \\
(\mathrm{kJ} / \mathrm{kg})\end{array}$} \\
\hline & & & & & $\begin{array}{c}\text { Dietary* } \\
\text { fibre }\end{array}$ & Galactomannan & & & \\
\hline Control 0 & 377 & 88 & 16 & 17 & 21 & 0 & 481 & 0 & 9784 \\
\hline Test : 50 & 410 & 80 & 14 & 15 & 19 & 27 & 435 & 32 & 8838 \\
\hline 100 & 462 & 71 & 13 & 14 & 17 & 49 & 374 & 59 & 7672 \\
\hline 150 & 527 & 59 & 12 & 15 & 14 & 64 & 309 & 77 & 6391 \\
\hline
\end{tabular}

* From Paul \& Southgate (1978).

† Starch, dextrins and sugars; calculated by difference: $100-$ (moisture + protein + ash + fat + total dietary fibre).

$\ddagger$ As replacement of wheat flour.

Subjects. The approval of an ethical referee was obtained for this study. Eleven subjects (seven female, four male; $23-54$ years; $94-116 \%, 106 \pm 2 \%$ ideal body-wt; Diem \& Lentner, 1972) fasted overnight on eight occasions separated by 1 week. On each occasion a sample of venous blood was taken from each subject who then ate bread with $25 \mathrm{ml}$ water. Further blood samples were taken 30 and 60 min after the meal had commenced.

Analytical methods. Blood samples were divided, part being deproteinized with trichloracetic acid and the supernatant fraction analysed for glucose by a glucose oxidase method (Werner et al. 1970), and part being used for preparation of serum for assay of insulin by radioimmunoassay method (Soeldner \& Sloane, 1965).

Blood glucose and insulin values were presented as means with their standard errors. Differences between test and control groups were calculated using a Student's $t$ test for paired values or Wilcoxor Rank-Sum test for paired values, as appropriate. Linear regressions and correlation coefficients for serum insulin values and rise of serum insulin values $v$. guar concentration were calculated using the least squares method; and the rise of serum insulin after guar with starch as a percentage of the rise of serum insulin after starch only was calculated from the regression equations, and plotted $v$. guar concentration (Fig. 4).

Sequence of meals. The meals were not taken in randomized order, as it was necessary that the first meal taken by each subject was $100 \mathrm{~g}$ bread containing $50 \mathrm{~g}$ starch, with no guar gum, in order to ensure that this produced reasonable insulin responses before proceeding with the rest of the study. The volunteers consumed bread on eight occasions according to the scheme in Table 1. Increasing the amounts of guar in the bread produces 
a dilution of starch. To eliminate the problem associated with starch reduction the volunteers were also required to eat control bread with starch levels corresponding to those of the guar bread. The eighth meal consisted of $100 \mathrm{~g}$ control bread ( $50 \mathrm{~g}$ starch) to obtain results which when compared with those from the first meal (50 g starch) gave statistical information about the variation of response within individuals. The composition of the test and control breads is shown in Table 2 .

\section{Satiety and acceptability}

Following the glucose-insulin study the satiating effect of control and test bread was assessed subjectively by using a numerical scoring system as previously adopted by Haber et al. (1977).

On eight separate occasions the eleven subjects were required to eat $100 \mathrm{~g}$ bread with $25 \mathrm{ml}$ water after an overnight fast. The volunteers were asked to indicate on a twenty-point scale their feeling of hunger or satiety. A hunger-satiety score was recorded just before eating, i.e. fasting, immediately after eating and at 60 and $120 \mathrm{~min}$ after the commencement of eating.

Over all, control and test bread at 50,100 and $150 \mathrm{~g} / \mathrm{kg}$ levels (see glucose-insulin study) were presented to each subject in random order, each level being duplicated.

Satiety values, presented as change of score in relation to fasting score, were expressed as means \pm SE (Table 3 ). Statistical tests were carried out by analysis of variance for a randomized block design and by Student's $t$ test for paired values.

During the satiety study, whilst consuming the bread, the subjects were also required to assess numerically their like or dislike of control and guar breads. The subjects were presented with a 'smiley chart' (Chapman \& Wigfield, 1970) and asked to indicate their response on a hedonic scale (Harper, 1979) numbered 1 (like very much) - 9 (dislike very much). The volunteers were able to produce an hedonic response for control bread and the three levels of guar bread. Hedonic scores were plotted $v$. percentage replacement of guar and expressed as means \pm SE. The significances of the differences were calculated by Student's $t$ test for paired values or the Wilcoxon Rank-Sum test for paried values.

\section{RESULTS}

Blood glucose. Fasting blood glucose values in all subjects were normal $4 \cdot 7 \pm 1 \cdot 3 \mathrm{mmol} / \mathrm{l}$. The differences between 30 and $60 \mathrm{~min}$ values and fasting values were small and variable (Figs. $1(a)$ and $2(a)$ ). The values obtained after guar bread were similar to those obtained after control bread with one exception; at $30 \mathrm{~min}$ after the $100 \mathrm{~g}$ guar $/ \mathrm{kg}$ bread when the rise of glucose above fasting values was significantly decreased $(P<0.05)$. Differences between controls (meals 1 and 8; Table 1) were minimal (variance ratio on 1 and $47 \mathrm{df} 1.50$ ).

Serum insulin. Fasting insulin values were normal $(9.6 \pm 0.6 \mathrm{mU} / \mathrm{l})$. There was no correlation between 30 min serum insulin levels after control breads and the dose of starch given (Fig. 1(b)), whereas after guar breads $30 \mathrm{~min}$ serum insulin levels were correlated inversely with starch dose and guar concentration $(r-0.55, P<0.001, n 54)$. At $30 \mathrm{~min}$, when compared with controls, serum insulin levels were significantly lower after 50 $(P<0.02)$ and $150(P<0.05$ by $t$ test, $P<0.02$ by Wilcoxon test $)$ but not after $100 \mathrm{~g}$ guar $/ \mathrm{kg}$ bread. There was a poor correlation between $60 \mathrm{~min}$ serum insulin levels after control breads and the dose of starch given $(r-0 \cdot 26, P<0 \cdot 1, n 54)$, but a strong correlation between $60 \mathrm{~min}$ insulin levels and starch dose and guar concentration $(r-0.50, P<0.001$, $n$ 54). At 60 min after guar-containing breads, serum insulin levels were significantly lower than after control breads at all three guar levels $(\mathrm{g} / \mathrm{kg})(50 P<0.05,100 P<0.001,150$ $P<0.05$ by $t$ test and Wilcoxon test, Fig. $2(b)$ ). Differences between controls (meals 1 and 8; Table 1) were minimal (variance ratio on 1 and $47 \mathrm{df} 0.33$ ).

Satiety. Analysis of variance of the values (Table 3 ) indicated a significant difference 

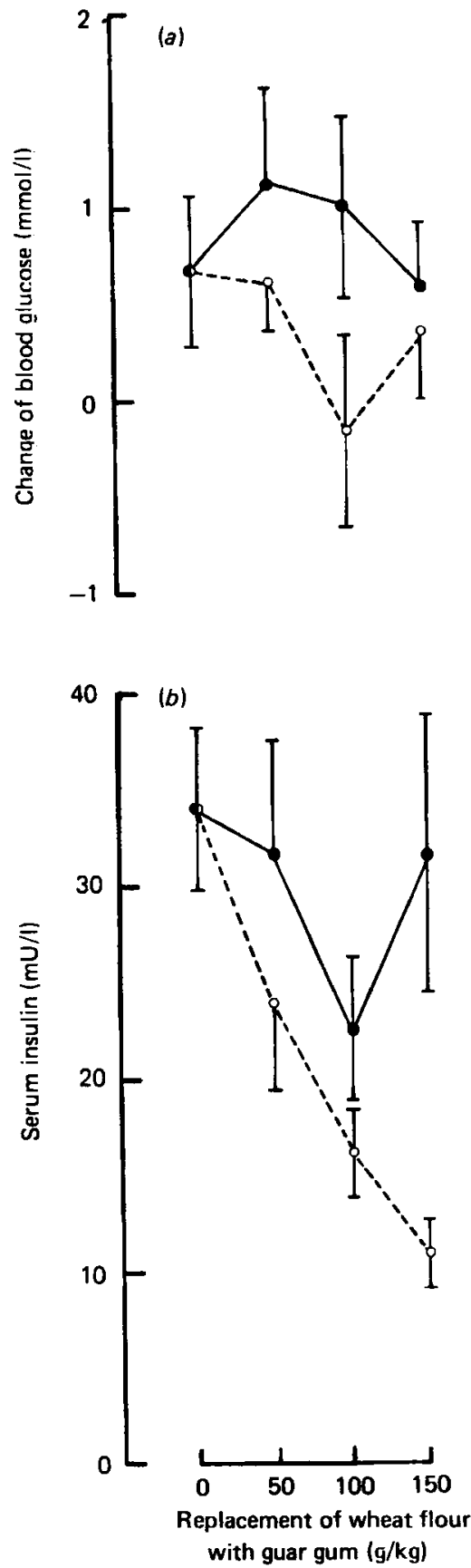

Fig. 1. (a) Change of blood gl cose (mmol/l) from fasting values $v$. replacement of wheat flour with guar gum $(\mathrm{g} / \mathrm{kg})$. Significant difference between control and $100 \mathrm{~g}$ guar $/ \mathrm{kg}$ breads $(P<0 \cdot 05)$. (b) Serum insulin $(\mathrm{mU} / \mathrm{l}) v$. replacement of wheat flour with guar gum $(\mathrm{g} / \mathrm{kg})$. Fasting values were $9.6 \pm 0.6 \mathrm{mU} / \mathrm{l}$. Significant differences between control guar bread at $50(P<0.02)$ and $150(P<0.02) \mathrm{g} / \mathrm{kg}$ levels. Points represent mean values with their standard errors represented by vertical bars $(n 11$, control $n 21)$ for control (O- ) and guar $1 \mathrm{O}_{---O}$ ) breads, at $30 \mathrm{~min}$. For details of meals, see Table 2. 

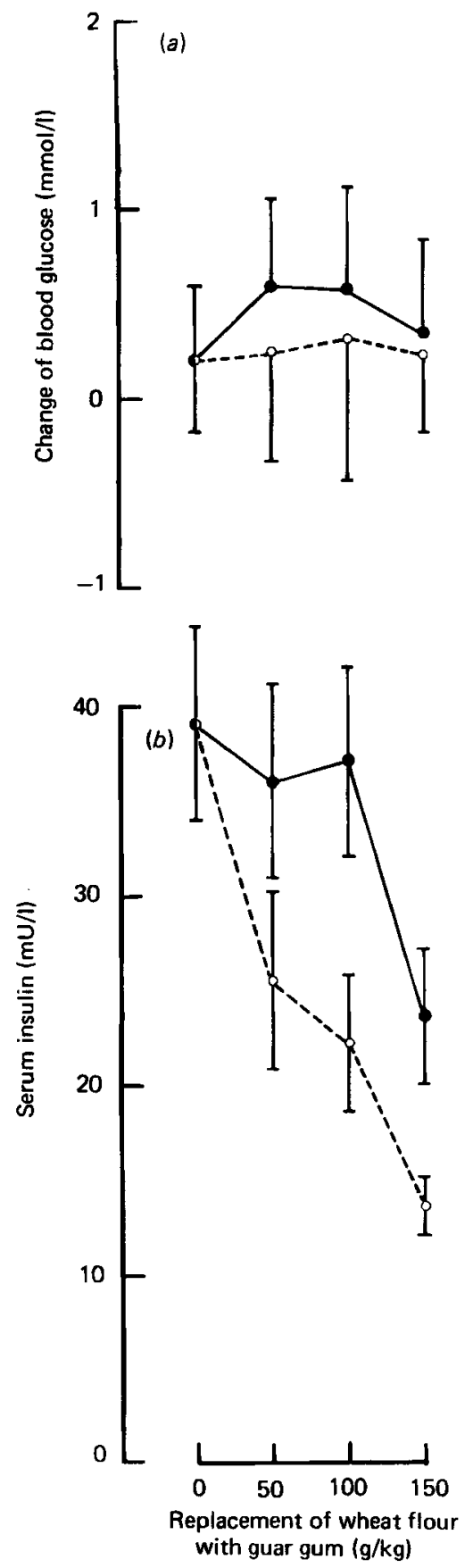

Fig. 2. (a) Change of blood glucose ( $\mathrm{mmol} / \mathrm{l})$ from fasting values $v$. replacement of wheat flour with guar gum $(\mathrm{g} / \mathrm{kg})$. No significant differences between control and guar breads. (b) Serum insulin (mU/l) $v$. replacement of wheat flour with guar gum $(\mathrm{g} / \mathrm{kg})$. Fasting values were $9.6 \pm 0.6 \mathrm{mU} / \mathrm{l}$. Significant differences between control and guar breads at $50(P<0.5), 100(P<0.001)$ and $150(P<0.05) \mathrm{g} / \mathrm{kg}$ levels. Points represent mean values with their standard errors represented by vertical bars $(n 11$, control $n$ 21) for control ( -1$)$ and guar $\left(\mathrm{O}_{--} \mathrm{O}^{-}\right.$breads, at $60 \mathrm{~min}$. For details of meals, see Table 2. 
Table 3. Satiety scores for control and test bread at different time intervals

(Change of score in relation to fasting score; mean values with standard error) $\dagger$

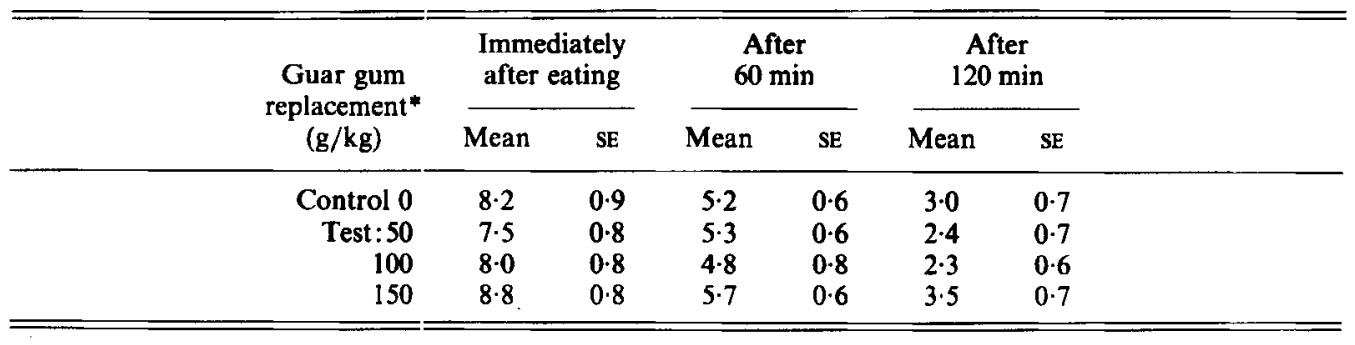

* As replacement of wheat flour.

+ Variance ratio, $2 \cdot 82$ (df 3 and 247 ); $P<0.05$.

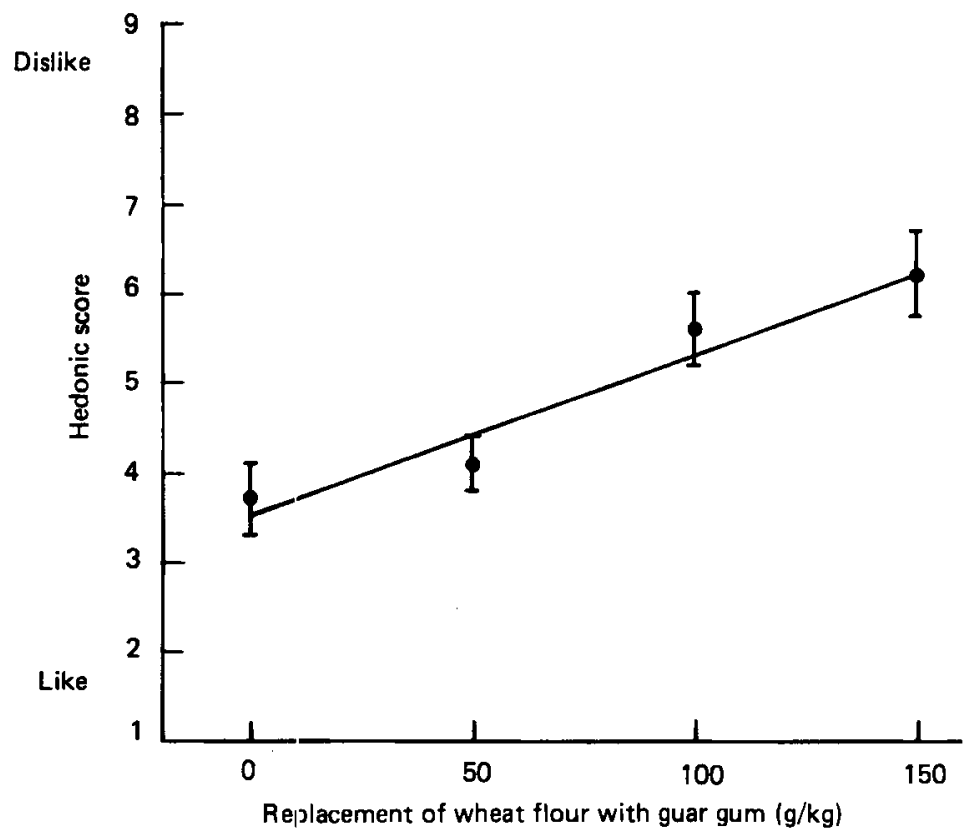

Fig. 3. Acceptability of contrcl and guar breads determined as hedonic score $v$. replacement of wheat flour with guar gum $(\mathrm{g} / \mathrm{kg})$. Hedonic scores on a nine-point scale; 9 represents dislike very much, 1 represents like very much and 5 is a neutral response. Points represent mean values with their standard errors represented by vertical bars. Regression equation $y=3.5+0.018 x, r 0.62, P<0.001, n 44$.

between the breads (variance ratio on 3 and 247 df $2.82 ; P<0.05$ ), but there was no statistical difference between control and guar breads at the three time intervals indicated: immediately after eating, 60 and 120 min (using Student's $t$ test).

However, the $150 \mathrm{~g}$ guar $/ \mathrm{kg}$ bread registered a higher satiety score than control at each of these time-periods and the re were significant increases in the satiety score due to the $150 \mathrm{~g}$ guar $/ \mathrm{kg}$ bread when compared with: $50 \mathrm{~g}$ guar $/ \mathrm{kg}$ bread immediately after eating $(P<0.05), 100 \mathrm{~g}$ guar $/ \mathrm{kg}$ bread at $60 \mathrm{~min}(P<0.02)$, and 50 and $100 \mathrm{~g}$ guar $/ \mathrm{kg}$ breads at $120 \mathrm{~min}$ (both $P<0.05$ ).

Acceptability. There was no significant difference in the hedonic score betweun control bread and $50 \mathrm{~g}$ guar $/ \mathrm{kg}$ bread; and between the 100 and $150 \mathrm{~g}$ guar $/ \mathrm{kg}$ breads (Fig. 3). 
A significant difference was found between: control and $100(P<0.01)$ and $150(P<0.01)$ $\mathrm{g}$ guar $/ \mathrm{kg}$ breads, and also between 50 and $100(P<0.002)$ and between 50 and 150 $(P<0.001$ by $t$ test, $P<0.01$ by Wilcoxon test) $\mathrm{g}$ guar $/ \mathrm{kg}$ breads. There was a positive correlation between hedonic score and relative replacement of guar $(r 0.62, P<0.001$ $n 44)$, regression equation $y=3 \cdot 5+0.018 x$.

\section{DISCUSSION}

The available carbohydrate in food is present mainly in the form of starch, with smaller quantities of dextrins and sugars. Our results show very small rises of blood glucose following normal bread, consistent with previous evidence of small responses to complex carbohydrate (Crapo et al. 1976). Furthermore, bread presented on its own, in a dry form but with a small amount of water, may by virtue of its dryness also contribute to a reduced rate of digestion and absorption, leading to a flattening of the postprandial rise in blood glucose. The use of dry meals to slow gastric emptying in patients with rapid gastric emptying and the dumping syndrome is well known to physicians. Work by Jenkins, Wolever, Taylor, Ghafari et al. (1980) supports the idea that the variable glycaemic response to different foods may be partly attributed to the variable rate of digestion. Variation in the glycaemic response to carbohydrate from potatoes and various cereal sources has recently been demonstrated (Crapo et al. 1977). In our study serum insulin values increased significantly after starch controls, but when subjects were given $100 \mathrm{~g}$ guar $/ \mathrm{kg}$ bread (equivalent to $59 \mathrm{~g}$ guar gum $/ \mathrm{kg}$ bread) serum insulin levels at $60 \mathrm{~min}$ were reduced by $48 \%$ (Fig. 4). Wolever et al. (1979) have produced similar results, demonstrating the efficacy of larger amounts of guar $(80 \mathrm{~g} / \mathrm{kg}$ bread) in substantially lowering serum insulin $(40 \%$ reduction).

The satiety values presented in Table 3 indicate that there are no significant differences between control and test breads, but there are slight increases in satiety with increasing levels of guar. As previously mentioned the starch content of bread is diluted by the incorporation of guar. This, combined with the elevated moisture content associated with guar addition (Table 2) meant that the assimilable solids content of the bread administered in the satiety study fell with increasing guar supplement. Accordingly, it seems likely that the satiating potential of the guar gum has been obscured by a reduction in the amount of starch in the test meal. Nevertheless feelings of satiation have been maintained by guar bread, despite a significant reduction in the energy content when compared to control $35 \%$ energy reduction for $150 \mathrm{~g}$ guar $/ \mathrm{kg}$ bread). However, the inclusion of starch-reduced controls into the satiety study, as was undertaken for the glucose-insulin study, would have provided a better comparison for the guar bread.

A prediction of the hedonic score at $100 \mathrm{~g} / \mathrm{kg}$ level calculated from the regression line produced a value of $5.3 \pm 0.4(P<0.05)$ indicating a neutral response (Fig. 3). The predictive score of $6.3 \pm 0.7(P<0.05)$ for $150 \mathrm{~g}$ guar $/ \mathrm{kg}$ bread suggests that the guar product at this level is unacceptable; descriptive terms used by the subjects included 'too moist', 'sticky crumb' and 'hard to swallow'. Levels of guar at 100 and $50 \mathrm{~g} / \mathrm{kg}$ seem to be quite acceptable; our subject group could not effectively distinguish between control and $50 \mathrm{~g} \mathrm{guar} / \mathrm{kg}$ bread. The presentation of the bread in a dry form, i.e. without butter, plus a small amount of drinking-water would certainly contribute to the high hedonic scores (decreased acceptability). Many of the volunteers found even the control bread difficult to eat. It would be interesting to investigate the acceptability of bread as consumed in the buttered form or even toasted. The authors found the toasted form of $150 \mathrm{~g} \mathrm{guar} / \mathrm{kg}$ bread to be delicious, but toasted bread was not used in this study because of uncertainties about thermal degredation.

Recently, Rivellese et al. (1980) have found that fibre-rich foods such as chick-peas (Cicer arietinum), beans (Phaseolus spp., Vigna spp., Vicia spp.), wholemeal bread, cabbage 

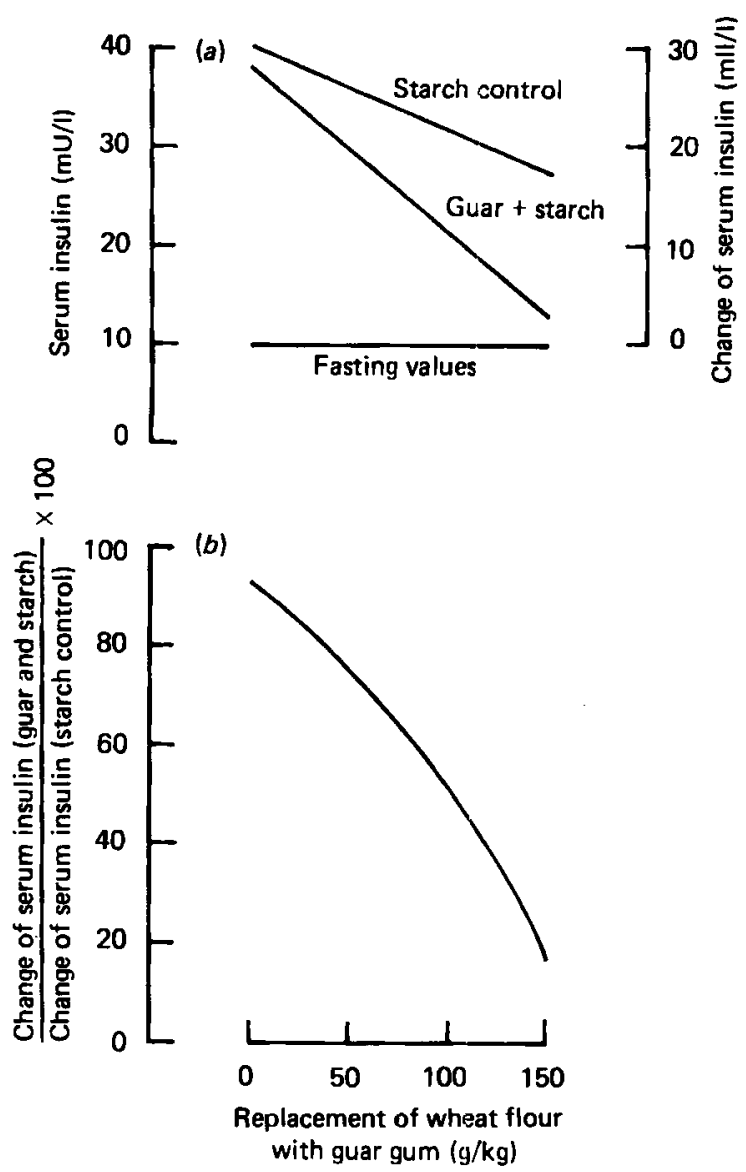

Fig. 4. (a) Linear regression lines (calculated from Fig. 3(b)) for control (starch only; $y=40-0.085 x$ ) and guar breads $(y=37 \cdot 3-0.166 x)$ of serum insulin $(\mathrm{mU} / \mathrm{l})$ and change of serum insulin $(\mathrm{mU} / \mathrm{l})$ in relation to fasting value at $60 \mathrm{~min} v$. replacement of wheat flour with guar gum $(\mathrm{g} / \mathrm{kg})$. (b) Dose response curve derived from regression lines. Change of serum insulin for guar and starch bread expressed as percentage of change of serum insulin for starch control only $v$. replacement of wheat flour with guar $\operatorname{gum}(\mathrm{g} / \mathrm{kg})$.

(Brassica oleracea) and cauliflower (B. oleracea var. botrytis), when fed to diabetics will improve blood glucose control. The same authors have proposed that, fibre-rich foods should be prescribed for diabetics because they are much better tolerated than dietary fibre supplements such as guar or pectin. However, very little evidence is available at present to support the validity of this claim. Fibre-rich diets, in whatever form, have caused slight problems of abdominal distension and flatus. As regards the organoleptic properties of guar, our work and that of Tredger \& Ransley (1978) seems to indicate that guar-supplemented products are acceptable to both normal and diabetic subjects. There is, of course, considerable individual variation in the acceptance of guar products, as there is with many foods and this is, therefore, an area of research which warrants further investigation.

In conclusion, our study has shown that the guar bread has produced a significant reduction of serum insulin at levels of $100 \mathrm{~g}$ guar $(59 \mathrm{~g} / \mathrm{kg}$ bread $) / \mathrm{kg}$ and above, and is acceptable at the $100 \mathrm{~g} / \mathrm{kg}$ level. Guar bread may also increase the satiating capacity of the diet; perhaps a study of the value of guar bread in controlling intake in obese diabetics is indicated. 
The authors wish to thank Dr R. Harper for his advice on the satiety and acceptability procedures, Dr M. J. Lewis for advice and encouragement, and the subjects for making this study possible.

Guar gum for incorporation into bread was provided by $\mathrm{Mr} \mathrm{K}$. W. Titchell and $\mathrm{Mr}$ S. J. Dickson of Hercules Limited.

A.R. L. was a Heinz Research Fellow.

\section{REFERENCES}

Apling, E. C., Khan, P. \& Ellis, P. R. (1978). Cereal Fd Wld 23, 640.

Apling, E. C., Leeds, A. R., Wolever, T. M. S. \& Jenkins, D. J. A. (1977). Lancet ii, 975.

Axford, D. W. E., Chamberlain, N., Collins, T. H. \& Elton, G. A. H. (1963). Cereal Sci. Today 8, 265.

Chamberlain, N., Collins, T. H. \& Elton, G. A. H. (1962). Bakers' Dig. 36, 52.

Chapman, L. D. \& Wigfield, R. (1970). Fd. Mf. 45, 59.

Crapo, P. A., Reaven, G. \& Olefsky, J. (1976). Diabetes 25, 741.

Crapo, P. A., Reaven, G. \& Olefsky, J. (1977). Diabetes 26, 1178.

Diem, K. \& Lentner, C. (1972). Documenta Geigy: Scientific Tables. Basle, Switzerland: J. R. Geigy.

Goldstein, A. M., Alter, E. N. \& Seaman, J. K. (1973). In Industrial Gums, p. 303 [R. L. Whistler \& J. N. Bemiller, editors]. London: Academic Press.

Haber, G. B., Heaton, K. W., Murphy, D. \& Burroughs, L. F. (1977). Lancet ii, 679.

Harper, R. (1979). In Preference Behaviour and Chemoreception, p. 123 [J. H. A. Kroeze, editor]. New York: Information Retrieval Inc.

Hill, M. A. \& Leeds, A. R. (1979). J. hum. Nutr. 33, 253.

Holt, S., Heading, R. C., Carter, D. C., Prescott, L. F. \& Tothill, P. (1979). Lancet i, 636.

Jenkins, D. J. A. (1980). Proc. Inst. Fd Sci. Technol. 13, 51.

Jenkins, D. J. A., Bloom, S. R., Albuquerque, R. H., Leeds, A. R., Sarson, D. L., Metz, G. L. \& Alberti, K. G. M. M. (1980a). Gut 21, 574.

Jenkins, D. J. A., Leeds, A. R., Gassull, M. A., Cochet, B. \& Alberti, K. G. M. M. (1977). Ann. int. Med. 86, 20.

Jenkins, D. J. A., Leeds, A. R., Gassull, M. A., Wolever, T. M. S., Goff, D. V., Alberti, K. G. M. M. \& Hockaday, T. D. R. (1976). Lancet ii, 172.

Jenkins, D. J. A., Wolever, T. M. S., Hockaday, T. D. R., Leeds, A. R., Howarth, R., Bacon, S., Apling, E. C. \& Dilawari, J. (1977). Lancet ii, 779.

Jenkins, D. J. A., Wolever, T. M. S., Leeds, A. R., Gassull, M. A., Haisman, P., Dilawari, J. B., Goff, D. V., Metz, G. L. \& Alberti, K. G. M. M. (1978). Br. med. J. i, 1392.

Jenkins, D. J. A., Wolever, T. M. S., Nineham, R., Taylor, R. H., Metz, G. L., Bacon, S. \& Hockaday, T. D. R. (1978). Br. med. J. ii, 1744.

Jenkins, D. J. A., Wolever, T. M. S., Taylor, R. H., Ghafari, H., Jenkins, A. L., Barker, H. \& Jenkins, M. J. A. (1980). Br. med. J. ii, 14.

Jenkins, D. J. A., Wolever, T. M. S., Taylor, R. H., Reynolds, D., Nineham, R. \& Hockaday, T. D. R. (1980). Br. med. J. $280,1353$.

Leeds, A. R., Bolster, N. R., Andrews, R. \& Truswell, A. S. (1979). Proc. Nutr. Soc. 38, 44 A.

Paul, A. A. \& Southgate, D. A. T. (1978). Spec Rep. med. Res Counc. no. 297.

Rivellese, A., Riccardi, G., Giacco, A., Pacioni, D., Genovese, S., Mattioli, P. L. \& Mancini, M. (1980). Lancet ii, 447.

Soeldner, J. S. \& Slone, D. (1965). Diabetes 14, 771.

Tredger, J. \& Ransley, J. (1978). J. hum. Nutr. 32, 427.

Werner, W., Rey, H. G. \& Wielinger, H. (1970). Z. analyt. Chem. 252, 224.

Wolever, T. M. S., Jenkins, D. J. A., Nineham, R. \& Alberti, K. G. M. M. (1979). Br. J. Nutr. $41,505$. 